\title{
Work-family conflicts and subsequent sleep medication among women and men: a longitudinal registry linkage study
}

\section{By Tea Lallukka, Sara Arber, M Laaksonen, Eero Lahelma and Ossi Rahkonen}

\author{
Abstract \\ Work and family are two key domains of life among working populations. Conflicts between paid \\ work and family life can be detrimental to sleep and other health-related outcomes. This study \\ examined longitudinally the influence of work-family conflicts to subsequent sleep medication. \\ Questionnaire data were derived from the Helsinki Health Study mail surveys in 2001-2002 (2929 \\ women, 793 men) of employees aged 40-60 years. Data concerning sleep medication were derived \\ from the Finnish Social Insurance Institution's registers covering all prescribed medication from \\ 1995 to 2007. Four items measured whether job responsibilities interfered with family life (work to \\ family conflicts), and four items measured whether family responsibilities interfered with work \\ (family to work conflicts). Cox proportional hazard models were fitted, adjusting for age, sleep \\ medication five years before baseline, as well as various family- and work-related covariates. \\ During a five year follow-up, $17 \%$ of women and $10 \%$ of men had at least one purchase of \\ prescribed sleep medication. Among women, family to work conflicts were associated with sleep \\ medication over the following 5 years after adjustment for age and prior medication $(\mathrm{HR}=2.03$, \\ 95\% CI 1.54-2.68). The association remained largely unaffected after adjusting for family-related \\ and work-related covariates. Work to family conflicts were also associated with subsequent sleep \\ medication after adjustment for age and prior medication (HR=1.43, 95\% CI 1.07-1.92). The \\ association attenuated after adjustment for work-related factors (HR=1.36, 95\% CI 0.98-1.89). No
}


associations could be confirmed among men. Thus reasons for men’s sleep medication likely emerge outside their work and family lives. Concerning individual items, strain-based ones showed stronger associations with sleep medication than more concrete time-based items. In conclusion, in particular family to work conflicts, but also work to family conflicts are clear determinants of women's sleep medication.

Keywords: hypnotics; work-family interface; prospective study; gender; sleep

\section{Introduction}

The increase in dual-earner families has exacerbated the difficulties of combining paid work and family life. Such difficulties are prevalent and have been associated with health and health-related outcomes (Frone et al., 1997; Frone et al., 1996; Winter et al., including self-reported sleep problems (Lallukka et al., 2010; Sekine et al., 2006). However, prospective studies on the influence of work-family conflicts on subsequent sleep problems are lacking. We lack especially more objective outcomes, such as sleep medication from register data, which reflects clinically significant sleep disorders while helping address recall bias and negative affectivity common to self-reported measures.

Theoretical framework for the study of work family interface and sleep medication

Work and family are two key domains of life among those of working age. Both women and men are almost equally involved in paid work in Finland, and there is a similar social trend of increased female labour force participation in other OECD countries (Jaumotte, 2003). Women's greater economic independence due to equal educational achievement and employment participation has been discussed in sociological research for several decades, highlighting wider opportunities among both genders in work and family spheres e.g. in choosing spouse, job, and 
fitting together participation patterns in family and work roles (Rapoport \& Rapoport, 1965).

However, given persistent findings that women undertake a greater share of domestic and childcare work than men (Fuwa, 2004; Knudsen \& Wærness, 2008), despite engagement in full-time work, it is important to consider the implications of work-family conflicts and whether these vary by gender.

Conceptually, work-family conflicts contain two separate dimensions, family to work conflicts and work to family conflicts (Grzywacz \& Marks, 2000). Family interferes with work, if family issues and responsibilities affect work performance. Work interferes with family, if job responsibilities interfere with family life such as fulfilling demands as a caregiver, a spouse or a parent. One might assume work to family conflicts to be more salient among women, and family to work conflicts among men, potentially dating back to women's traditional role as a caregiver at home ('expressive role’) and men’s role as a breadwinner ('instrumental role’) (Parsons, 1951). Also more recent evidence suggests that where work demands interfere with an individuals' ability to manage their roles as a caregiver or a spouse it could be more detrimental to women than men, while family roles acting as barriers to success at work could have more adverse consequences among men (Frone, 2000; Frone et al., 1996). Thus, on average, women may continuously take more responsibility for or worry more about family matters, whereas for men, job may take higher priority. Such norms and expectations may affect how women and men perceive their roles at home and work, and deal with the contradicting demands between the two domains. Accordingly, previous studies have suggested that paid work represents an additional workload in particular for women (Bartley et al., 1992). However, current evidence suggests that the overall prevalence and level of work to family and family to work conflicts are relatively similar among women and men (Chandola et al., 2004; Kinnunen \& Mauno, 1998). Also results of a meta-analysis showed that levels of family to work and work to family conflicts are similar among women and men suggesting that gender is unlikely an antecedent of work-family conflicts (Byron, 2005). Furthermore, gender was not a moderator of the associations between work domain antecedents of work-family conflicts 
or family domain antecedents of family to work conflicts in another recent meta-analysis (Michel et al., 2011). Despite this similarity between women and men, it is possible that gender differences exist in how work-family conflicts exert their effects on health. Nonetheless, no support for gender differences was found in an earlier study focusing on the importance of work-family conflicts to mental health (Frone, 2000).

A possible explanation for conflicts between paid work and family life is related to imbalance between multiple roles as parent, employee, and spouse, which causes strain and has detrimental effects on health and well-being (Barnett, 2004). An alternative explanation suggests that such multiple roles are protective and beneficial for women. This protective effect is linked with the 'role enhancement hypothesis', as work outside the home can provide women with more social networks and opportunities which support women’s health and well-being (Grzywacz \& Marks, 2000). Accordingly, evidence among women in Britain and Finland suggests that multiple roles are beneficial for women's health (Lahelma et al., 2002). The 'role strain hypothesis' is highlighted in this study focusing on both work and family as sources of strain and the two dimensions of work-family conflicts, namely work to family and family to work conflicts (Grzywacz \& Marks, 2000).

The antecedents of work-family conflicts are expected to vary for work to family versus family to work conflicts (Byron, 2005; Michel et al., 2011). Results from meta-analyses suggest that work-related factors are stronger determinants of work to family conflicts, while nonwork and family-related factors such as family stressors and family characteristics are primarily determinants of family to work conflicts (Byron, 2005; Michel et al., 2011). Previous longitudinal evidence suggests that work-related factors such as shift work and family-related factors such as caregiving increase work-family conflicts among men, whereas social support at the workplace and high job control may protect from such conflicts (Jansen et al., 2003). In turn, among women, workrelated and family-related risk factors for work-family conflicts may include physical workload, 
working overtime, and having dependent children, but having domestic help may be protective of work to family conflict. In line with this evidence, an earlier Finnish study found that family to work conflicts were explained by family-related factors, such as number of children, while work to family conflicts were explained by work-related factors such as job contract and leadership (Kinnunen \& Mauno, 1998). The evidence about the antecedents of work-family conflicts is of importance when examining these conflicts and their influence on health-related outcomes, such as sleep problems and sleep medication. Thus including work- and family-related factors allows analysis of the influence of work-family conflicts on sleep medication after these potential antecedents of work-family conflicts and sleep medication have been taken into account.

\section{Previous evidence linking work-family conflicts to sleep}

The consequences of work-family conflicts for sleep are not well understood. Some cross-sectional studies have found associations between work-family conflicts and sleep problems (Lallukka et al., 2010; Nylén et al., 2007; Sekine et al., 2006), while a positive work-family spillover has been associated with better sleep quality among women (Williams et al., 2006). A Finnish cross-sectional study reported associations between interpersonal conflicts at work and at home and self-reported use of tranquilizers and hypnotics (Appelberg et al., 1993).

However, longitudinal studies are needed since the direction of the association cannot be judged from cross-sectional evidence. Furthermore, as both work-family conflicts and sleep problems have primarily been based on self-reported measures, it is important to confirm previous findings using prospective data and more objective outcomes in order to address reporting bias and capture clinically significant, more severe sleep problems. Sleep medication from register data provides a measure of such clinically significant sleep problems, as data about prescribed medication requires a prescription from a physician, who has assessed the severity of sleep problems. Although, sleep medication is prevalent in the general and in the working population 
(Kronholm et al., 2008) the social determinants of sleep medication are poorly understood. As sleep problems typically increase after the age of 40 (Sivertsen et al., 2009), a middle-aged cohort is most suitable to examine such determinants of sleep medication. Since work-family conflicts are intertwined with multiple roles, including marital status, living arrangements, and working conditions (Chandola et al., 2004; Roos et al., 2007), a broader range of family and work characteristics should be considered, when examining the influence of work-family conflicts to subsequent sleep problems and sleep medication.

We hypothesize that work-family conflicts influence poor sleep as indicated by sleep medication and that these influences remain even after considering key work-related and familyrelated antecedents of both conflicts and poor sleep. Furthermore, we hypothesize that the influences are stronger among women than men, because of differences in gender roles as well as job types and other work-related factors. We also hypothesize that family to work conflicts will show stronger influences on sleep medication than work to family conflicts due to differences in their antecedents.

\section{Methods}

\section{Data}

Data were derived from the Helsinki Health Study baseline mail surveys collected in 2001-2002 (3124 women, 845 men); a sample of all employees aged 40-60 years working for the City of Helsinki at baseline. Data concerning sleep and other psychotropic medication were derived from the Finnish Social Insurance Institution's registers covering all prescribed medication for 5 years before and after baseline from 1995 to 2007. The Helsinki Health Study has received ethical approvals from the Department of Public Health, University of Helsinki, and the City of Helsinki, Finland. We obtained informed written consent to link baseline questionnaire responses to the register data on medication. Consent was received from $74 \%$ of the respondents. These linkages 
were done using personal identification numbers given to each Finnish resident. Non-response analyses have shown that these data are broadly representative of the target population, and that consent giving for register linkages followed similar patterns (Laaksonen, et al., 2008).

\section{Sleep medication}

The outcome was any prescribed and reimbursed hypnotic or other sleep medication purchase over a 5 year follow-up since the date of returning the baseline questionnaire. Such prescriptions and following purchases can be assumed to indicate subsequent medication use. All reimbursed sleep medication is included in the register, thus the focus is on more persistent and severe sleep problems exceeding the threshold for reimbursement criteria. The Classification of drugs was based on World Health Organization's ATC (Anatomic Therapeutic Chemical) codes (WHO Collaborating Centre for Drug Statistics Methodology, 2009). The ATC-codes used are estimated to cover practically all sleep medication in Finland (full code list used to examine sleep medication is available from the first author upon request). The outcome was the first purchase of any sleep medication in the five years after baseline taking into account time to the purchase after baseline. Those using any of the examined sleep medications at baseline, judged on the basis of defined daily doses (DDDs) of the last purchase before baseline, were excluded from all analyses $(n=319)$. Any other previous sleep medication during the five years before baseline was adjusted for in the analyses. All participants working for the City of Helsinki have access to the occupational health care system provided by the employer and are entitled to similar reimbursements for their medication purchases.

\section{Work-family conflicts}

Four items were used to measure work to family conflicts and four items to measure family to work conflicts. The items were taken from the US National Study of Midlife Development 
(Grzywacz \& Marks, 2000), and they measure negative spillover from work to family and from family to work. Positive spillover was not included, as this study is focused on work-family conflicts as exposures, not buffers. Work to family items measured whether job responsibilities interfered with family life: 1 . Your job reduces the amount of time you can spend with the family, 2. Problems at work make you irritable at home, 3. Your work involves a lot of travel away from home, and 4. Your job takes so much energy you do not feel up to doing things that need attention at home. Family to work items measured whether family responsibilities interfered with work: 1 . Family matters reduce the time you can devote to your job, 2. Family worries or problems distract you from your work, 3. Family activities stop you getting the amount of sleep you need to do your job well, and 4. Family obligations reduce the time you need to relax or be by yourself. Four response alternatives were given: 'not at all', ‘to some extent', 'a great deal', and 'I don't have a family’. No specific instructions to define ‘family' were given in the questionnaire. Those who ticked the response alternative of 'no family' (6\%) were excluded in all analyses, as work-family conflicts are relevant only to those who are employed and have a family. Other response alternatives scored from one to three points, thus sum scores to examine work to family conflicts and family to work conflicts varied from 4 to 12. The scores were divided into low (score of 4), weak (scores 5-7), and strong conflicts (scores 8-12). In addition, each of the eight items was examined separately using the original response alternatives (scores 1-3) to provide a more detailed understanding of the influence of the work-family conflicts to sleep medication. Pearson correlation coefficient between the family to work and work to family sum scores was 0.38 supporting separate examination of these two dimensions of work-family conflicts (Grzywacz \& Marks, 2000). The Cronbach's alpha for family to work conflicts was 0.74 and for work to family conflicts was 0.56. Individual item correlations varied from low to moderate, and are displayed in an online Appendix. 


\section{Covariates}

Two sets of covariates were examined: family-related and work-related factors. Family-related covariates included marital status, children, social support, and social networks. Marital status comprised single, married/cohabiting, divorced, and widowed. The respondents were asked to report how many children they had and how old the children were. Number of children under 18 years of age living in the same household was used as a covariate. Social support was measured by Sarason's inventory (short version), which asked about all sources of social support such as the opportunities to receive help and emotional support in different situations from spouse, friends, neighbours, colleagues, or supervisors (Sarason et al., 1983; Sarason et al., 1987). Social networks referred to the number of friends and relatives that the respondent met at least once during four weeks. The response alternatives in the items ranged from none to 11 or more for both items. Work-related factors included physical and psychosocial working conditions, and work arrangements. Working hours were classified as 1-29 hours a week, 30-40 hours a week, 4150 hours a week, and more than 50 hours a week. Shift work was classified into four groups: daytime work, rotating daytime shifts without night-time work, night-time work only, and other work arrangements. Physical working conditions were measured by an 18 item inventory from the Finnish Institute of Occupational Health (Piirainen et al., 2003). Three factors comprised physical workload, namely repetitive movements and awkward postures, environmental exposures such as noise, and sedentary work using computers. Psychosocial working conditions were measured by Karasek’s job content questionnaire (Karasek, 1985), which included 9 items on job control and 9 items on job demands. Job strain, i.e. interaction of these two dimensions was adjusted for as a covariate. Further details of the measurement of covariates can be found elsewhere (Laaksonen et al., 2011; Lallukka, 2008; Lallukka et al., 2010). 


\section{Statistical analyses}

Cox proportional hazard models (Hazard Ratios (HR) and their 95\% confidence intervals (95\% CI)) were fitted separately for men and women using days until the first purchase of prescribed sleep medication after baseline as the time axis. Models were adjusted first for age using five year age intervals (model 1), and second for sleep medication five years before the baseline (model 2). The two sets of covariates were then added to model 2. We examined separately, whether family-related covariates (marital status, children in the household, social support and social networks, model 3), and work-related covariates (working hours, physical working conditions, and psychosocial working conditions, model 4), affected the studied associations. The rationale for this modelling was to examine whether family-related covariates had a stronger contribution to family to work conflicts, and whether work-related covariates had a stronger contribution to work to family conflicts, as previously suggested (Kinnunen \& Mauno, 1998).

Sensitivity analyses were conducted excluding those with any previous sleep medication during five years before the baseline $(n=587,16 \%)$. The results were largely similar, but the associations were slightly stronger (data not shown). The analyses were also repeated using logistic regression analysis and the results were again similar, but somewhat stronger and more robust to adjustment. We preferred to retain all the data to avoid selection by covariates, and to use Cox regression analysis, which enables taking into account time to the event, i.e., days to the first medication purchase as described above. As the importance of work-family conflicts may vary between genders, and sleep medication is more prevalent among women, all the analyses were conducted stratified by gender. Multiplicative interactions were tested by adding an interaction term of gender and work-family conflicts in a Cox regression model. Although the strength of the estimates and statistical significance of the examined associations varied between women and men, no gender interactions were found concerning either family to work conflicts or work to family 
conflicts. Further sensitivity analyses showed that the associations were equally found using a follow-up time of 1, 2, 3, 4, and 5 years. All the analyses were conducted using an SAS programme, version 9.2 .

\section{Results}

During the five year follow-up, $17 \%$ of women and $10 \%$ of men had at least one purchase of prescribed sleep medication (Table 1). 'Strong' conflicts from family to work were reported by $9 \%$ of women and $7 \%$ of men, and over a third of both women and men reported 'weak' conflicts. Work to family conflicts were more prevalent than family to work conflicts. Nearly two thirds of women and men had 'weak' work to family conflicts, and 'strong' work to family conflicts were reported by $17 \%$ of women and men. Concerning the individual items, typically only $1-3 \%$ of participants reported that family issues interfered with work to a great extent, except that $8 \%$ of women reported that family obligations reduced their time for relaxation. More men than women reported that their work involved at least some travelling away from home, while more women than men reported that their job took so much energy that they did not feel up to doing things at home.

'Strong' family to work conflicts were associated with subsequent sleep medication among women after adjusting for age (HR=2.42, 95\% CI 1.83-3.18, Table 2, model 1). Adjusting further for prior sleep medication in the five years before baseline somewhat attenuated the association, whereas adjusting for family-related factors and work-related factors did not attenuate the association (models 3 and 4). Additionally, 'weak' family to work conflicts were associated with subsequent sleep medication after adjusting for age (HR=1.55; 95\% CI 1.28-1.88). This association survived all the adjustments and remained practically unaffected.

Among women the associations of work to family conflicts with subsequent sleep medication were somewhat weaker than those for family to work conflicts. Women with strong work to family conflicts were more likely to have sleep medication after adjusting for age 
(HR=1.74, 95\% CI 1.30-2.34), and after adjusting for prior sleep medication the association attenuated (HR=1.43, 95\% CI 1.07-1.92). Adjustment for family-related factors had negligible contribution to the association, but after adjusting for work-related factors, the association slightly weakened and was of borderline statistical significance (HR=1.36, 95\% CI 0.98-1.89). No associations were found between 'weak' work to family conflicts and subsequent sleep medication. Among men, family to work conflicts were unassociated with sleep medication (Table 2). Concerning work to family conflicts, patterns of the association concerning 'strong' work to family conflicts were similar to those for women, but did not reach statistical significance.

In order to better understand which specific work-family conflicts were associated with subsequent sleep medication, and whether this differed for men and women, we examined each of the eight items in the two work-family conflict scales. Table 3 shows associations following age adjustment (model 1) and adjustment for sleep medication five years before baseline (model 2). Models 3 and 4 are not presented for the individual items. Among women, for three of the four family to work conflict items, associations between such conflicts and subsequent sleep medication were found after adjusting for age and prior sleep medication: if family worries or problems distracted the respondent from their work (HR 1.88, 95\% CI 1.06-3.35), if family activities were reported to stop them from getting the amount of sleep they needed (HR 2.19, 95\% CI 1.39-3.45), and if family obligations were reported to reduce the time the women needed to relax or be themselves (HR 1.65, 95\% CI 1.22 -2.24). However, no association was found if family matters reduced the time the women could devote to their job. These associations applied to women reporting such conflicts to 'a great extent'. The corresponding associations were found also for women reporting that such conflicts existed to some extent.

For the four work to family conflict items, associations with subsequent sleep medication were found after adjusting for age and prior medication among women (Table 3) if problems at work were reported to make the respondents irritable at home (HR 1.74, 95\% CI 1.29- 
2.36), and if their job was reported to take so much energy that the respondent did not feel up to doing things that needed attention at home (HR 1.68, 95\% CI 1.27-2.21). However, sleep medication was unassociated with items regarding whether the job reduced the amount of time the woman could spend with her family, or if their job required a lot of travel away from home.

Among men, the individual items were mostly unassociated with subsequent sleep medication (Table 3). However, in contrast to women, men who reported that their job reduced the amount of time they could spend with the family to some extent had a higher risk for subsequent sleep medication (HR 1.64, 95\% CI 1.02-2.65). In addition, men who reported that their job involved a lot of travel away from home had a higher risk for sleep medication (over the five year follow-up), after adjusting for age and prior sleep medication (HR 3.08, 95\% CI 0.96-9.94).

\section{Discussion}

This study examined the influence of family to work and work to family conflicts to subsequent sleep medication over a five year follow-up period. Clear associations between family to work conflicts and subsequent sleep medication were found among women, but not among men. Work to family conflicts showed a somewhat weaker association with sleep medication among women, but associations could not be confirmed among men. Adjustment for family-related and work-related factors made only a modest contribution to the examined associations. Individual items that were used to measure the work-family interface had varied influence to sleep medication. Strain-based items such as conflicts involving worries, irritability, and lack of energy or time for relaxation were strongly associated with subsequent sleep medication among women, while the influence of time-based items such as having sufficient time to devote to their job or be with their family was negligible. 
Interpretation

Our results support previous notions about work-family conflicts as a form of interrole conflict, where there is incompatibility between roles at work and home (Greenhaus \& Beutell, 1985). Our results further emphasize the significance of strain-based conflicts over the time-based ones. As our study was prospective and sleep medication a register based outcome, and we were able to show the robustness of the associations by adjusting for prior sleep medication, this highlights the strength of our findings.

Clear associations were found in this longitudinal study between family to work and work to family conflicts and subsequent sleep medication among women. This is in line with previous cross-sectional evidence about the associations with sleep problems and adds prospective evidence on the direction of the associations (Lallukka et al., 2010; Nylén et al., 2007; Sekine et al., 2006). While our research suggests that for women, family to work conflicts have a greater influence on sleep medication than work to family conflicts, among men the reverse was suggested but could not be confirmed. Also mental disorders are more typical consequences of family to work than work to family conflicts (Frone et al., 1992). These results are also in line with recent results showing that family to work conflicts had more long term consequences than work to family conflicts, and that the associations were found among women only (Kinnunen et al., 2010). Sleep was not included, but our results support the gender differences and potentially varying significance of family roles and influence of family pressures which could lead to more detrimental consequences for sleep among women.

There are further potential explanations for the differences in the influence of family to work and work to family conflicts to sleep. Family-related conflicts are likely to be more proximal or their reasons more difficult to change than work-related conflicts. For example, if family to work conflicts arise from situations where the respondent becomes a lone-parent, or takes 
on caring for a chronically sick family member, both time- and strain-based conflicts may follow, with little opportunities to alter these situations. Instead, work-related issues that cause conflicts are likely to be more distal, and may also be more reversible or changeable, for example through modification of working conditions or changing jobs.

The lack of associations among men using the objective measure of sleep medication contrasts with previous cross-sectional evidence on self-reported sleep problems (Lallukka et al., 2010; Sekine et al., 2006). It is possible that cross-sectional studies have provided biased results, or that men with sleep problems are less likely than women to seek treatment and obtain sleep medication. Nonetheless, gender differences emphasise the significance of family to work conflicts to women's sleep medication in particular. Although no statistically significant findings could be confirmed among men, the associations appeared to be stronger for work to family conflicts than for family to conflicts among men, as judged by the effect sizes.

Gender differences in the nature of work-family conflicts were revealed by our analysis of the individual items. These showed that in particular strain-based items such as familyrelated demands and worry have strong associations with women’s sleep medication. Instead, among men, all of the associations were practically non-existent, except an association for work interfering with time spent with family and one suggested for work involving travelling. The latter association concerning work involving travel away from home and sleep medication among men has not been previously reported. Although the effect size appeared to be large, the number of men reporting such conflicts was low $(n=15)$, and statistical significance was not reached. This limits strong conclusions and the public health significance is likely minor, as compared to more frequent conflicts. Alternatively, this item may not represent a work-family conflict per se, but may reflect that long commutes to work, spending parts of the week away from home, or work-related travel is associated with sleep medication, irrespective of how any of these 'travel away from home' factors influence family life. This item also had low correlations with other items. As none of the previous 
studies have focused on the individual items, it is not possible to compare the findings for sleep or other health-related outcomes.

Analysis of the strain-based and time-based items separately further showed that their influence on sleep is different and summed scales mask these differences. These differences are important to consider in further studies focused on consequences of work-family conflicts. Although previous studies have not examined influence of time-based and strain-based items to sleep separately, the results are in line with evidence on different antecedents of such time-based and strain-based conflicts (Greenhaus \& Beutell, 1985). Thus reasons for time-based conflicts are likely to be more concrete, whereas strain-based conflicts may involve more mental pressures that are likely to be detrimental to sleep.

Previous studies have not examined the influence of work-family conflicts to sleep using register data on prescribed sleep medication, a prospective design and controlling for prior sleep medication. A nationwide Finnish study from the early 1990s, however, examined separately conflicts at work and with spouse, and use of tranquilizers, hypnotics, and analgesics (Appelberg et al., 1993). In contrast to our study, the associations were stronger and more consistent among men. The results cannot be directly compared, as interference between the domains was not a focus of the previous study, medication was self-reported, and the study was cross-sectional. Our results are also in line with studies linking work-family conflicts with depressive and other mood disorders in particular and with mental health problems in general (Chandola et al., 2004; Frone, 2000).

In contrast to earlier evidence and hypotheses about antecedents for work-family conflicts (Ford et al., 2007; Kinnunen \& Mauno 1998), family-related and work-related factors had a modest or negligible contribution to the examined associations. For example, one might have assumed that adjusting for working hours would contribute to the examined associations, as parttime employees’ by definition are less exposed to work-related factors and have more time to participate in family activities. However, part-time work can also cause conflicts, as part-time work 
may be a compromise, less rewarding, and involve even more roles (Hall \& Gordon, 1973)

Furthermore, part-time employees may need to take full responsibility for domestic work, alongside involuntary part-time work. Although control over working hours likely helps combine paid work with family life and prevent adverse health effects (Ala-Mursula et al., 2006), the associations in our study remained after job strain and working hours were taken into account. Also being a loneparent, having a large family and low social support could have been assumed to emerge as antecedents of work-family conflicts (Greenhaus \& Beutell, 1985) contributing to the examined associations, but this was not found. Instead, taking into account prior medication led to attenuation of the associations. This was expected, as sleep problems and their medication tend to be persistent with limited evidence on efficiency or benefits of treatment (Riemann et al., 2011). It is possible that our measures of family and work-related factors did not cover key antecedents of the workfamily interface, or reasons for the found associations between work-family conflicts and sleep medication are beyond the examined sociodemographic, family- and work-related factors. For example, personal and familial characteristics, division of housework, and care-giving were not included. These factors might also shed light on the found gender differences in this study. Furthermore, the influence of family to work conflicts to women's sleep medication in particular might reflect different gender roles and unequal share of domestic work. More detailed elaboration of these effects is, however, beyond the scope of this study.

\section{Methodological Consideration}

This study has several strengths. First, the study uses objective data about sleep medication based on registers covering all prescribed reimbursed medication purchases over a 10 year period. Thus these data reflect clinically significant sleep problems. Register data also helps avoid the reporting bias that is common within studies that examine self-reported outcomes. Furthermore, we were able to examine all sleep medication in the 5 years prior to the baseline 
survey, and show that the associations between work-family conflicts and subsequent sleep medication remained albeit attenuated after prior medication was taken into account. The associations also remained clear for incident sleep medication in the following 5 years when all those with any prior sleep medication purchases before baseline were excluded from the analyses. The inclusion of register data about prior sleep medication is of particular importance, as it at least partly rules out selection and helps address causality issues.

A further strength of our study was the opportunity to examine both dimensions of work-family conflicts: namely work interfering with family, and family interfering with work, and all of the individual work-family conflict items (Grzywacz \& Marks, 2000). Additional key antecedents and covariates of both dimensions were included, to examine whether the associations were explained by these factors. To confirm that the associations were not specific to the selected work-family conflict cut-off points, additional sensitivity analyses were conducted using a lower cut-off point for 'strong' family to work conflicts (data not shown). Results were similar, and we preferred to use the same cut-off points for both work-family conflict dimensions. We also conducted sensitivity analysis to examine the co-existence of both types of work-family conflicts. Such coexistence of conflicts remained associated with subsequent sleep medication among women (data not shown). Finally, we were able to examine individual work-family conflict items, as well as both women and men to show the gender differences in the influence of work-family conflicts to subsequent sleep medication.

Several limitations of this study need to be acknowledged. First, the purchases of prescribed sleep medication do not directly capture the use of and adherence to sleep medication. Neither do they directly capture sleep-related problems. Although such medication is prescribed by a physician, not all those with sleep problems seek treatment and medication. It is a limitation that we were unable to capture any untreated sleep problems or sleep problems treated with nonpharmacological measures. Further studies could elucidate the significance of work-family conflicts 
to sleep problems untreated with medication. Second, the indications for the examined sleep medication prescriptions were unavailable. Although the medications examined here are typically prescribed for common sleep problems such as insomnia, some of these medications may also be used for treatment of other medical conditions as well. Sleep problems are often co-morbid with mental and somatic ill-health, and a risk factor for subsequent morbidity (Baglioni et al., 2011; Paunio et al., 2009; Roth, 2009).

As all participants were 40 to 60 years old and employed at the baseline, the healthy worker effect may have attenuated the associations between work-family conflicts and sleep medication (Wilcosky \& Wing, 1987). Thus, it is possible that women and men who continue in their jobs in middle-age, and combine their job with family life, are likely to be healthier or more robust to counter the potential detrimental effects of work-family conflicts and other work or family-related demands than those who are not employed. This could be a problem particularly for women as it may be easier and more acceptable for women to withdraw from working life and stay home if such problems arise, while social background and working conditions may have been adapted to the conflicting demands at work and home among those continuously employed. Accordingly, the prevalence of both sleep problems and sleep medication has been found to be higher among unemployed people in earlier studies (Arber \& Meadows, 2011; Hyyppä et al., 1997). As some of the study population was 60 years at baseline, many of them retired during follow-up. To ensure that change in employment status did not affect the results, we conducted sensitivity analyses excluding 60-year-olds from the data. The results, however, remained very similar and even slightly strengthened. It is possible that work-family conflicts at baseline have a long-lasting, persistent influence on sleep, and that this remains even after removal of work-related exposures and roles after retirement. Moreover, as the outcome was time to the first sleep medication purchase, this typically occurred at earlier phases of follow-up when most participants were continuously employed. 
Concerning gender differences, lack of power may have contributed to the statistically non-existent associations among men. In our cohort, as within the Finnish public sector in general, only $20 \%$ of all employees are men. Thus the numbers of men reporting strong conflicts were relatively low as compared to women. While the strength and direction of the estimates concerning work to family conflicts among men were similar to women, family to work conflicts showed no associations. Finally, sleep medication captures only part, but this is likely to be the most severe and chronic part of sleep problems. Transient and occasional sleep problems are more likely to be selfmedicated, addressed using personal strategies such as alcohol use (as a sleep aid), or remain untreated (Kaneita et al., 2007; Souza et al., 2002).

\section{Conclusion}

Work-family conflicts, in particular family to work conflicts are associated with sleep medication, but only among women. Achieving a better balance between paid work and family life likely helps prevent insomnia and reduces the need for sleep medication among women. Strainbased items related to the woman's family life such as worry, irritability, lack of energy and lack of time for relaxation were most strongly associated with sleep medication. In contrast, time-based items such as reporting a lack of time to devote to work or a family life had practically non-existent associations with sleep medication. Work-family conflicts could not be confirmed as antecedents of men's sleep medication which may be more affected by factors outside the work-family interface. 


\section{References}

Ala-Mursula, L., Vahtera, J., Kouvonen, A., Väänanen, A., Linna, A., Pentti, J. et al. (2006). Long hours in paid and domestic work and subsequent sickness absence: Does control over daily working hours matter? Occupational and Environmental Medicine, 63(9), 608-616.

Appelberg, K., Romanov, K., Honkasalo, M. L., \& Koskenvuo, M. (1993). The use of tranquilizers, hypnotics and analgesics among 18,592 Finnish adults: Associations with recent interpersonal conflicts at work or with a spouse. Journal of Clinical Epidemiology, 46(11), 1315-1322.

Arber, S., \& Meadows, R. (2011). Social and health patterning of sleep quality and duration. In S. McFall, \& C. Garrington (Eds.). Understanding society: Early findings from the first wave of the UK's household longitudinal study (pp. 88-98) Colchester: ISER, University of Essex.

Baglioni, C., Battagliese, G., Feige, B., Spiegelhalder, K., Nissen, C., Voderholzer, U. et al. (2011). Insomnia as a predictor of depression: A meta-analytic evaluation of longitudinal epidemiological studies. Journal of Affective Disorders, 135(1-3), 10-19.

Barnett, R. C. (2004). Women and multiple roles: Myths and reality. Harvard Review of Psychiatry, 12(3), 158-164.

Bartley, M., Popay, J., \& Plewis, J. (1992). Domestic conditions, paid employment and women's experience of ill-health. Sociology of Health \& Illness, 14(3), 313-343.

Byron, K. (2005). A meta-analytic review of work-family conflict and its antecedents. Journal of Vocational Behavior, 67(2), 169-198.

Chandola, T., Martikainen, P., Bartley, M., Lahelma, E., Marmot, M., Michikazu, S. et al. (2004). Does conflict between home and work explain the effect of multiple roles on mental health? A 
comparative study of Finland, Japan, and the UK. International Journal of Epidemiology, 33(4), 884-893.

Ford, M. T., Heinen, B. A., \& Langkamer, K. L. (2007). Work and family satisfaction and conflict: A meta-analysis of cross-domain relations. The Journal of Applied Psychology, 92(1), 57-80.

Frone, M. R. (2000). Work-family conflict and employee psychiatric disorders: The national comorbidity survey. The Journal of Applied Psychology, 85(6), 888-895.

Frone, M. R., Russell, M., \& Cooper, M. L. (1997). Relation of work-family conflict to health outcomes : A four-year longitudinal study of employed parents. Journal of Occupational and Organizational Psychology, 70(4), 325-335.

Frone, M. R., Russell, M., \& Cooper, M. L. (1992). Antecedents and outcomes of work-family conflict: Testing a model of the work-family interface. The Journal of Applied Psychology, 77(1), 65-78.

Frone, M. R., Russell, M., \& Barnes, G. M. (1996). Work-Family conflict, gender, and healthrelated outcomes : A study of employed parents in two community samples. Journal of Occupational Health Psychology, 1(1), 57-69.

Fuwa, M. (2004). Macro-level gender inequality and the division of household labor in 22 countries. American Sociological Review, 69(6), 751-767.

Greenhaus, J. H., \& Beutell, N. J. (1985). Sources of conflict between work and family roles. The Academy of Management Review, 10(1), 76-88. 
Grzywacz, J. G., \& Marks, N. F. (2000). Reconceptualizing the work-family interface: An ecological perspective on the correlates of positive and negative spillover between work and family. Journal of Occupational Health Psychology, 5(1), 111-126.

Hall, D. T., \& Gordon, F. E. (1973). Career choices of married women: Effects on conflict, role behavior, and satisfaction. Journal of Applied Psychology, 58(1), 42-48.

Hyyppä, M. T., Kronholm, E., \& Alanen, E. (1997). Quality of sleep during economic recession in finland: A longitudinal cohort study. Social Science \& Medicine, 45(5), 731-738.

Jansen, N. W., Kant, I., Kristensen, T. S., \& Nijhuis, F. J. (2003). Antecedents and consequences of work-family conflict: A prospective cohort study Journal of Occupational and Environmental Medicine, 45(5), 479-491.

Jaumotte, F. (2003). Female labour force participation: Past trends and main determinants in OECD countries. OECD Publishing.

Kaneita, Y., Uchiyama, M., Takemura, S., Yokoyama, E., Miyake, T., Harano, S. et al. (2007). Use of alcohol and hypnotic medication as aids to sleep among the Japanese general population Sleep Medicine, 8(7-8), 723-732.

Karasek, R. A. (1985). Job content questionnaire and user's guide. Department of Work Environment, University of Massachusetts, Lowell, MA.

Kinnunen, U., Feldt, T., Mauno, S., \& Rantanen, J. (2010). Interface between work and family: A longitudinal individual and crossover perspective. Journal of Occupational \& Organizational Psychology, 83(1), 119-137. 
Kinnunen, U., \& Mauno, S. (1998). Antecedents and outcomes of work-family conflict among employed women and men in Finland. Human Relations, 51(2), 177-177.

Knudsen, K., \& Wærness, K. (2008). National context and spouses’ housework in 34 countries. European Sociological Review, 24(1), 97-113.

Kronholm, E., Partonen, T., Laatikainen, T., Peltonen, M., Härmä, M., Hublin, C. et al. (2008). Trends in self-reported sleep duration and insomnia-related symptoms in Finland from 1972 to 2005: A comparative review and re-analysis of Finnish population samples. Journal of Sleep Research, 17(1), 54-62.

Laaksonen, M., Aittomäki, A., Lallukka, T., Rahkonen, O., Saastamoinen, P., Silventoinen, K. et al. (2008). Register-based study among employees showed small nonparticipation bias in health surveys and check-ups. Journal of Clinical Epidemiology, 61(9), 900-906.

Laaksonen, M., Lallukka, T., Lahelma, E., \& Partonen, T. (2011, Mar 29). Working conditions and psychotropic medication: A prospective cohort study. Social Psychiatry and Psychiatric Epidemiology,

Lahelma, E., Arber, S., Kivelä, K., \& Roos, E. (2002). Multiple roles and health among British and Finnish women: The influence of socioeconomic circumstances. Social Science \& Medicine (1982), 54(5), 727-740.

Lallukka, T. (2008). Associations Among working conditions and behavioral risk factors: The Helsinki health study with international comparisons (electronic version available at university of Helsinki, http://ethesis.helsinki.fi/en/). (Doctoral dissertation, University of Helsinki), 1-168. 
Lallukka, T., Chandola, T., Roos, E., Cable, N., Sekine, M., Kagamimori, S. et al. (2010). Workfamily conflicts and health behaviors among British, Finnish, and Japanese employees. International Journal of Behavioral Medicine, 17(2), 134-142.

Lallukka, T., Rahkonen, O., Lahelma, E., \& Arber, S. (2010). Sleep complaints in middle-aged women and men: The contribution of working conditions and work-family conflicts. The Journal of Sleep Research, 19, 466-477.

Michel, J. S., Kotrba, L. M., Mitchelson, J. K., Clark, M. A., \& Baltes, B. B. (2011). Antecedents of work-family conflict: A meta-analytic review. Journal of Organizational Behavior, 32(5), 689725.

Nylén, L., Melin, B., \& Laflamme, L. (2007). Interference between work and outside-work demands relative to health: Unwinding possibilities among full-time and part-time employees. International Journal of Behavioral Medicine, 14(4), 229-236.

Parsons, T. (1951). The social system. Glencoe, IL: The Free Press.

Paunio, T., Korhonen, T., Hublin, C., Partinen, M., Kivimäki, M., Koskenvuo, M. et al. (2009). Longitudinal study on poor sleep and life dissatisfaction in a nationwide cohort of twins. American Journal of Epidemiology, 169(2), 206-213.

Piirainen, T., Hirvonen, M., Elo, A., Huuhtanen, P., Kandolin, I., Kauppinen, K. et al. (2003). The work and health interview study 2003. Basic report. In Finnish. (Työ ja terveys haastattelututkimus 2003. Taulukkoraportti). Helsinki: The Finnish Institute of Occupational Health (Työterveyslaitos).

Rapoport, R., \& Rapoport, R. (1965). Work and family in contemporary society. American Sociological Review, 30(3), pp. 381-394. 
Riemann, D., Spiegelhalder, K., Espie, C., Pollmacher, T., Léger, D., Bassetti, C. et al. (2011). Chronic insomnia: Clinical and research challenges--an agenda. Pharmacopsychiatry, 44(1), 114.

Roos, E., Sarlio-Lähteenkorva, S., Lallukka, T., \& Lahelma, E. (2007). Associations of work-family conflicts with food habits and physical activity. Public Health Nutrition, 10(3), 222-229.

Roth, T. (2009). Comorbid insomnia: Current directions and future challenges. The American Journal of Managed Care, 15 Suppl, S6-13.

Sarason, I. G., Levine, H. M., Basham, R. B., \& Sarason, B. R. (1983). Assessing social support: The social support questionnaire. Journal of Personality and Social Psychology, 44(1), 127139.

Sarason, I. G., Sarason, B. R., Shearin, E. N., \& Pierce, G. R. (1987). A brief measure of social support: Practical and theoretical implications. Journal of Social and Personal Relationships, 4, 497-510.

Sekine, M., Chandola, T., Martikainen, P., Marmot, M., \& Kagamimori, S. (2006). Work and family characteristics as determinants of socioeconomic and sex inequalities in sleep: The Japanese civil servants study. Sleep, 29(2), 206-216.

Sivertsen, B., Krokstad, S., Overland, S., \& Mykletun, A. (2009). The epidemiology of insomnia: Associations with physical and mental health. the HUNT-2 study. Journal of Psychosomatic Research, 67(2), 109-116.

Souza, J. C., Magna, L. A., \& Reimao, R. (2002). Insomnia and hypnotic use in campo grande general population, brazil Arquivos De Neuro-Psiquiatria, 60(3-B), 702-707. 
WHO Collaborating Centre for Drug Statistics Methodology. (2009). Guidelines for ATC classification and DDD assignment, 2010. Oslo: WHO Collaborating Centre for Drug Statistics.

Wilcosky, T., \& Wing, S. (1987). The healthy worker effect. selection of workers and work forces. Scandinavian Journal of Work, Environment \& Health, 13(1), 70-72.

Williams, A., Franche, R. L., Ibrahim, S., Mustard, C. A., \& Layton, F. R. (2006). Examining the relationship between work-family spillover and sleep quality. Journal of Occupational Health Psychology, 11(1), 27-37.

Winter, T., Roos, E., Rahkonen, O., Martikainen, P., \& Lahelma, E. (2006). Work-family conflicts and self-rated health among middle-aged municipal employees in Finland. International Journal of Behavioral Medicine, 13(4), 276-285. 
NB. Some of the figures in the tables below differ slightly from those in the final version published of the paper in Social Science and Medicine. 
Table 1. Family to work and work to family conflicts, and sleep medication among women and men aged 4060 at baseline ${ }^{\mathrm{a}}(\%)$

\section{Family to work conflicts (summed scale)}

Work to family conflicts (summed scale)

Family worries or problems distract you from your work ${ }^{\mathrm{b}}$

\section{Family to work conflicts (items)}

Family matters reduce the time you can devote to your job

$$
\begin{array}{r}
\text { No } \\
\text { Weak } \\
\text { Strong }
\end{array}
$$

Women $(n=3124)$

$$
\begin{aligned}
& 47 \\
& 39
\end{aligned}
$$$$
8
$$

Weak

Strong

To great extent

$$
\begin{array}{r}
\text { Not at all } \\
\text { To some extent } \\
\text { To great extent }
\end{array}
$$

Family activities stop you getting the amount of sleep you need to do your job well

\footnotetext{
Not at all To some extent To great extent
}

Family obligations reduce the time you need to relax or be yourself

$$
\begin{array}{r}
\text { Not at all } \\
\text { To some extent }
\end{array}
$$

To great extent

\section{Work to family conflicts (items)}

Your job reduces the amount of time you can spend with the family

$$
\begin{array}{r}
\text { Not at all } \\
\text { To some extent } \\
\text { To great extent }
\end{array}
$$

Problems at work make you irritable at home

$\begin{array}{rr}\text { Not at all } & 38 \\ \text { To some extent } & 50 \\ \text { To great extent } & 7\end{array}$

Your work involves a lot of travel away from home

$\begin{array}{rcc}\text { Not at all } & 87 & 70 \\ \text { To some extent } & 7 & 22 \\ \text { To great extent } & 1 & 2\end{array}$

p-value (for overall gender differences in the distributions)

Your job takes so much energy you do not feel up to doing things that need attention at home

$\begin{array}{rccc}\text { Not at all } & 41 & 56 & \\ \text { To some extent } & 45 & 35 & <0.0001 \\ \text { To great extent } & 9 & 3 & <0.0001 \\ & 18 & 11 & 0.0001\end{array}$

Seep medication use in 5 years after baseline 17 
${ }^{\mathrm{b}}$ among men intermediate and frequent conflicts were combined, due to very few men reporting these conflicts. Gender difference (p-value) was tested using full distributions 
Table 2. Family to work and work to family conflicts and subsequent sleep medication in a five-year follow-up. Cox regression analysis among women $(n=3124)$ and men $(n=845)$ aged 40-60 at baseline, Helsinki Health Study, Finland

\begin{tabular}{|c|c|c|c|c|c|c|c|}
\hline & $\begin{array}{l}\text { MODEL } 1 \\
\text { (age-adjusted) }\end{array}$ & & $\begin{array}{l}\text { MODEL } 2 \\
\text { (Model } 1 \\
+ \text { previous sleep medication) }\end{array}$ & & $\begin{array}{l}\text { MODEL } 3 \\
\text { (Model 2+ } \\
\text { family-related covariates) }\end{array}$ & & $\begin{array}{l}\text { MODEL } 4 \\
\text { (Model } 2 \\
+ \text { work-related cova }\end{array}$ \\
\hline \multicolumn{8}{|l|}{ Women } \\
\hline (a) Family to work conflicts & HR & $95 \%$ CI & HR & $95 \%$ CI & HR & $95 \%$ CI & HR \\
\hline No & 1.00 & & 1.00 & & 1.00 & & 1.00 \\
\hline Weak & 1.51 & $(1.25-1.84)$ & 1.50 & $(1.23-1.81)$ & 1.53 & $(1.25-1.87)$ & 1.46 \\
\hline Strong & 2.33 & $(1.77-3.07)$ & 1.97 & $(1.50-2.60)$ & 2.01 & $(1.51-2.66)$ & 1.92 \\
\hline \multicolumn{8}{|l|}{ Work to family conflicts } \\
\hline No & 1.00 & & 1.00 & & 1.00 & & 1.00 \\
\hline Weak & 1.19 & $(0.93-1.53)$ & 1.05 & $(0.81-1.35)$ & 1.06 & $(0.82-1.37)$ & 1.01 \\
\hline Strong & 1.70 & $(1.27-2.27)$ & 1.40 & $(1.04-1.87)$ & 1.38 & $(1.03-1.85)$ & 1.32 \\
\hline \multicolumn{8}{|l|}{ Men } \\
\hline (b) Family to work conflicts & HR & $95 \%$ CI & HR & $95 \%$ CI & HR & $95 \%$ CI & HR \\
\hline No & 1.00 & & 1.00 & & 1.00 & & 1.00 \\
\hline Weak & 1.00 & $(0.63-1.59)$ & 0.98 & $(0.61-1.56)$ & 1.04 & $(0.64-1.67)$ & 0.90 \\
\hline Strong & 0.94 & $(0.40-2.22)$ & 0.88 & $(0.37-2.07)$ & 0.98 & $(0.41-2.33)$ & 0.73 \\
\hline \multicolumn{8}{|l|}{ Work to family conflicts } \\
\hline No & 1.00 & & 1.00 & & 1.00 & & 1.00 \\
\hline Weak & 0.97 & $(0.54-1.73)$ & 1.00 & $(0.56-1.78)$ & 1.02 & $(0.57-1.84)$ & 0.92 \\
\hline Strong & 1.57 & $(0.81-3.06)$ & 1.51 & $(0.78-2.93)$ & 1.77 & $(0.89-3.50)$ & 1.27 \\
\hline
\end{tabular}

Model 1 Age adjusted for (5 year age groups)

Model 2 Model 1+ previous sleep medication

Model 3 Model 2+ marital status, number of children, social support and social networks adjusted for

Model 4 Model 2+ working overtime, physical and psychosocial working conditions adjusted for 
Table 3. Work-family conflicts and subsequent sleep medication in a five-year follow-up. Cox regression analysis among women ( $\mathrm{n}=3124)$ and men ( $\mathrm{n}=845$ ) aged $40-60$ at baseline, Helsinki Health Study, Finland

\section{Family to work conflicts}

Family matters reduce the time you can devote to your job

Family worries or problems distract you from your work

$\begin{array}{rrr}\text { Not at all } & 1.00 & \\ \text { To some extent } & 1.13 & (0.89-1.42) \\ \text { To great extent } & 0.75 & (0.34-1.69)\end{array}$

$\begin{array}{rrr}\text { Not at all } & 1.00 & \\ \text { To some extent } & 1.61 & (1.32-1.96) \\ \text { To great extent } & 2.69 & (1.52-4.79)\end{array}$

Family activities stop you getting the amount of sleep you need to do your job well

$\begin{array}{rrr}\text { Not at all } & 1.00 & \\ \text { To some extent } & 2.10 & (1.73-2.56) \\ \text { To great extent } & 3.39 & (2.16-5.33)\end{array}$

Family obligations reduce the time you need to relax or be yourself

$\begin{array}{rrr}\text { Not at all } & 1.00 \\ \text { To some extent } & 1.49 \quad(1.24-1.81)\end{array}$

\section{Work to family conflicts}

To great extent $\quad 1.83 \quad(1.35-2.48)$

Your job reduces the amount of time you can spend with the family

Problems at work make you irritable at home

$\begin{array}{rcc}\text { Not at all } & 1.00 & \\ \text { To some extent } & 1.08 & (0.90-1.30) \\ \text { To great extent } & 0.98 & (0.73-1.33) \\ & & \\ \text { Not at all } & 1.00 & \\ \text { To some extent } & 1.39 & (1.15-1.69) \\ \text { To great extent } & 2.11 & (1.56-2.85) \\ & & \\ \text { Not at all } & 1.00 & \\ \text { To some extent } & 0.88 & (0.62-1.23) \\ \text { To great extent } & 1.20 & (0.45-3.21)\end{array}$

Your work involves a lot of travel away from home

To great extent 1.20
that need attention at home

Your job takes so much energy you do not feel up to doing things that need attention at home

\begin{tabular}{|c|c|c|c|c|c|c|c|c|}
\hline & HR & CI 95\% & HR & CI 95\% & HR & CI 95\% & HR & CI 95\% \\
\hline Not at all & 1.00 & & 1.00 & & 1.00 & & 1.00 & \\
\hline some extent & 1.13 & $(0.89-1.42)$ & 1.07 & $(0.85-1.36)$ & 0.86 & $(0.51-1.46)$ & 0.93 & $(0.55-1.58)$ \\
\hline great extent & 0.75 & (0.34 -1.69) & 0.77 & $(0.34-1.73)$ & 0.59 & $(0.08-4.26)$ & 0.84 & $(0.12-6.11)$ \\
\hline Not at all & 1.00 & & 1.00 & & 1.00 & & 1.00 & \\
\hline some extent & 1.61 & $(1.32-1.96)$ & 1.43 & $(1.17-1.74)$ & 1.43 & $(0.90-2.29)$ & 1.24 & $(0.77-2.00)$ \\
\hline great extent & 2.69 & $(1.52-4.79)$ & 1.84 & $(1.03-3.28)$ & & & & \\
\hline \multicolumn{9}{|l|}{ our job well } \\
\hline Not at all & 1.00 & & 1.00 & & 1.00 & & 1.00 & \\
\hline some extent & 2.10 & $(1.73-2.56)$ & 1.81 & $(1.49-2.21)$ & 1.51 & $(0.88-2.59)$ & 1.38 & $(0.80-2.36)$ \\
\hline great extent & 3.39 & (2.16 -5.33) & 2.10 & $(1.33-3.31)$ & 0.92 & $(0.13-6.64)$ & 0.60 & $(0.08-4.37)$ \\
\hline Not at all & 1.00 & & 1.00 & & 1.00 & & 1.00 & \\
\hline some extent & 1.49 & $(1.24-1.81)$ & 1.58 & $(1.3-1.91)$ & 0.60 & (0.35 -1.01) & 0.56 & $(0.33-0.95)$ \\
\hline great extent & 1.83 & $(1.35-2.48)$ & 1.64 & $(1.21-2.21)$ & 1.22 & $(0.44-3.39)$ & 1.21 & $(0.44-3.36)$ \\
\hline Not at all & 1.00 & & 1.00 & & 1.00 & & 1.00 & \\
\hline some extent & 1.08 & $(0.90-1.30)$ & 1.12 & $(0.93-1.34)$ & 1.36 & $(0.85-2.17)$ & 1.64 & $(1.02-2.63)$ \\
\hline great extent & 0.98 & $(0.73-1.33)$ & 0.90 & $(0.67-1.21)$ & 1.29 & $(0.65-2.53)$ & 1.45 & $(0.74-2.86)$ \\
\hline Not at all & 1.00 & & 1.00 & & 1.00 & & 1.00 & \\
\hline some extent & 1.39 & $(1.15-1.69)$ & 1.25 & $(1.03-1.52)$ & 1.38 & $(0.88-2.15)$ & 1.21 & $(0.78-1.89)$ \\
\hline great extent & 2.11 & $(1.56-2.85)$ & 1.72 & $(1.27-2.32)$ & 0.73 & $(0.22-2.37)$ & 0.77 & $(0.24-2.50)$ \\
\hline Not at all & 1.00 & & 1.00 & & 1.00 & & 1.00 & \\
\hline some extent & 0.88 & $(0.62-1.23)$ & 0.87 & $(0.62-1.23)$ & 1.35 & $(0.84-2.18)$ & 1.44 & $(0.89-2.33)$ \\
\hline great extent & 1.20 & $(0.45-3.21)$ & 1.29 & $(0.48-3.45)$ & 2.34 & $(0.73-7.50)$ & 3.31 & $(1.03-10.67)$ \\
\hline \multicolumn{9}{|c|}{ need attention at home } \\
\hline Not at all & 1.00 & & 1.00 & & 1.00 & & 1.00 & \\
\hline some extent & 1.35 & $(1.12-1.64)$ & 1.17 & $(0.97-1.42)$ & 1.27 & $(0.81-1.98)$ & 1.13 & $(0.72-1.77)$ \\
\hline great extent & 2.06 & $(1.57-2.71)$ & 1.65 & $(1.25-2.17)$ & 2.42 & $(1.03-5.69)$ & 1.58 & $(0.66-3.75)$ \\
\hline
\end{tabular}

$\begin{array}{ccc}\text { Model 2 } & \text { MEN } & \text { Model 2 } \\ \text { (Model 1+ previous sleep } & \text { Model 1 } \\ \text { medication) } & \text { (age-adjusted) } & \text { (Model 1+ previous sleep } \\ \text { medication) }\end{array}$


